\title{
Effectiveness of Diamond Blades in the Turning of Aluminium Composites
}

\author{
Paweł Karolczak ${ }^{1 *}$, Marek Kołodziej ${ }^{1}$, Maciej Kowalski ${ }^{1}$ \\ 1 Department of Machine Tools and Mechanical Engineering Technologies, Faculty of Mechanical Engineering, \\ Wroclaw University of Technology and Science, Łukasiewicza 5, 50-371 Wrocław, Poland \\ * Corresponding author's e-mail: pawel.karolczak@pwr.edu.pl
}

\begin{abstract}
Owing to their excellent strength-to-weight ratio aluminium composite materials are very readily used in the construction of means of transport. The parts made of such materials must be characterized by high reliability and workmanship. Hence, machining is the predominant method of manufacturing parts from composites. The problem with the turning, milling and drilling of ceramic-reinforced composites is the abrasive action of the reinforcement, resulting in heavy wear of the blades and so in lower surface quality and dimensional-shape accuracy and higher manufacturing costs. A solution to this problem can involve the blades made of superhard materials or properly matched conditions of machining with sintered carbide blades. This paper presents the results of the turning tests carried out on an aluminium composite material reinforced with long ceramic fibres. An uncoated sintered carbide blade is compared with a diamond coated blade and a polycrystalline diamond blade. Post-turning surface roughness and machining forces were selected as the main indicators of cutting ability. The effect of the blades on the forming chips is shown and the higher resistance of the polycrystalline diamond blades to the abrasive action of the reinforcing fibres is confirmed by microscopic photographs. Besides the confirmation of the higher durability of the diamond blades, the conditions in which when using these blades one can achieve better machining effects than the ones achievable by the compared tools are defined. Moreover, it is shown that by properly matching the machining parameters and aiding machining with oil mist lubrication, it is possible to obtain excellent surface quality by means of carbide blades. The minimum quantity lubrication also increases the life of the blades.
\end{abstract}

Keywords: composite materials, superhard blade, surface roughness, cutting forces, chips.

\section{INTRODUCTION}

The current rapid development of means of transport concentrates on the introduction of innovative structural materials. The main requirements which must be met by such materials are very good strength properties at a low specific weight. The properties should not change even at elevated temperatures. Moreover, the structural materials used in means of transport must be characterized by high resistance to wear, high thermal conductivity and low thermal expansion [19]. The materials should not only meet the high requirements, but also be relatively inexpensive. Today, when industry pursues profitability and there is an increasing emphasis on the environmental protection, the selection of a proper structural material is even more important. The composites based on metals satisfy the above-mentioned requirements very well. Aluminium alloys, titanium alloys, copper alloys and magnesium alloys are most often used for the matrix of composites. They are the most sought after materials in various branches of the aviation industry, the aerospace industry, the automotive industry and in military applications [20]. The composites in which an aluminium alloy is the matrix, are usually reinforced with deposited particles or fibres. Ceramic compounds, e.g. $\mathrm{SiC}$ and $\mathrm{Al}_{2} \mathrm{O}_{3}$, but also graphite, are used as the reinforcing material [11]. The main important difference between the fibrereinforced composites and the particle-reinforced composites consists in the directionality of their properties. The material reinforced with particles 
is isotropic, whereas the fibre-reinforced composites are generally anisotropic. The matrix endows the manufactured product with a shape and protects its load-bearing reinforcement. For example, an addition of $\mathrm{Al}_{2} \mathrm{O}_{3}$ fibres strengthens the microstructure and reduces the propagation of matrix cracks in the areas between the fibres, thus reducing the plastic strains in the matrix and thus fatigue plasticity [7]. The most often used methods of producing ceramic-reinforced aluminium composites are: casting, powder metallurgy and spray deposition [23]. In the case of low shapedimensional requirements, these advanced manufacturing methods make it possible to produce ultimately shaped and dimensioned composites as machine components. On the other hand, because of the high safety factors which must be met by means of transport, the quality requirements for the manufactured components are very high. Therefore, manufacturing methods ensuring the required dimensional tolerance and a proper surface finish are indispensable in the production cycle [18]. Such a method is machining.

The machinability of the metal-matrix (including aluminium-matrix) composites is the subject of extensive research. The greater hardness of the composite in comparison with the matrix material improves the surface layer formation conditions (less intensive build-up). Unfortunately, a few cases when reinforcement particles were pulled out of the composite surface, adhering to and building up on the cutting tool, have been reported [15]. The ceramic reinforcement has abrasive properties and poses a serious hazard to cutting blades. Their abrasive wear is much faster than during the machining of aluminium alloys [21]. Since the reinforcement is harder than the popular high-speed steels, the latter cannot be used to machine the composites. In order to reduce the cutting blade wear, the following tools are suggested: polycrystalline diamond blades, regular boron nitride blades and tungsten carbide blades [1]. Since these are very expensive tools, sintered carbide blades or ceramic blades can be used instead (at properly matched machining parameters)[10]. For machining the alumina fibrereinforced or silicon carbide particle-reinforced aluminium composites, the tool life of a carbide tool and that of a diamond tool would be comparable only for machining at low cutting speeds combined with a small depth of cut and a high rate of feed [6]. The volumetric amount of the reinforcement in the composite and the diameter of the fibres or particles have the strongest effect on the wear of polycrystalline diamond blades. The larger the amount and size of the reinforcement, the shorter the life of the blade [9]. Despite the high resistance of diamond to abrasive wear, there is a limit speed above which the wear of diamond blades considerably increases. For example, diamond blades cannot be used effectively when milling a composite reinforced with a $65 \%$ volumetric fraction of $10 \mu \mathrm{m} \mathrm{SiC} \mathrm{particles} \mathrm{at} \mathrm{a}$ speed of above $300 \mathrm{~m} / \mathrm{min}$ [26]. An interesting phenomenon was observed when machining an aluminium composite reinforced with short fibres and particles by means of tools made of respectively uncoated carbide and coated carbide [24]. Below the cutting speed of $250 \mathrm{~m} / \mathrm{min}$, cracks and spalls appeared, while above this speed the abrasive wear of the tool flank increased considerably. Other studies showed that the increase in the blade wear at higher machining parameters does not depend on whether the carbide tool is coated or not [2]. On the other hand, it was found that during the machining of aluminium composites reinforced with silicon carbide $(\mathrm{SiC})$, tools with a CVD (chemical vapour deposition) diamond coating wear out quicker than polycrystalline diamond (PCD) inserts [1].

The machining parameters and the kind of tool material have a major bearing not only on the tool life, but also on the machining properties (e.g. the cutting force) and machining effects (e.g. surface roughness). It was observed that at a higher cutting speed, the matrix deforms less and the tool tears out and shears the reinforcement more than pulls it out of the matrix. At the same time, as the cutting speed increases, the cutting force and the feed force decrease [8]. The decrease in the cutting force with increasing cutting speed is ascribed to the higher temperature in the shear plane, resulting in a reduction in the shear strength of the machined material [22]. The quality of the surface (especially its roughness and the absence of surface and near-surface defects) is the most important machining effect for means of transport. Numerous studies indicate that using polycrystalline diamond blades or regular boron nitride blades, one can obtain a less rough surface than the one obtained using carbide blades $[17,25]$. At low feed rates, it is even possible to obtain mirror-like surfaces [4]. Even though the depth of cut does not shorten tool life considerably, it adversely affects the surface quality. As the depth of cut increases, so does roughness and 
Table 1. Chemical composition of AlSi9Mg alloy [16]

\begin{tabular}{|c|c|c|c|c|c|c|c|c|}
\hline \multirow{2}{*}{ Alloy designation } & \multicolumn{7}{|c|}{ Element concentration, \% } \\
\cline { 2 - 10 } & $\mathrm{Si}$ & $\mathrm{Cu}$ & $\mathrm{Mg}$ & $\mathrm{Mn}$ & $\mathrm{Fe}$ & $\mathrm{Ti}$ & $\mathrm{Zn}$ & $\mathrm{Al}$ \\
\hline $\mathrm{AC}-\mathrm{AlSi9Mg}$ & 9.5 & $<0.05$ & 0.35 & $<0.1$ & $<0.18$ & 0.15 & $<0.07$ & rest \\
\hline
\end{tabular}

Table 2. Selected properties of AlSi9Mg alloy [16]

\begin{tabular}{|c|c|c|c|c|}
\hline \multirow{2}{*}{ Alloy designation } & \multicolumn{4}{|c|}{ Minimal properties } \\
\cline { 2 - 5 } & $R_{m} \mathrm{MPa}$ & $R_{0,2} \mathrm{MPa}$ & $A_{50 \mathrm{~mm},} \%$ & $H B$ \\
\hline AC-AISi9Mg & 230 & 190 & 2 & 75 \\
\hline
\end{tabular}

microcracks can appear in the surface layer [5]. The research aimed at optimizing the machining of composites [12] shows that surface roughness is most affected by the rate of feed, followed by the depth of cut, whereas the speed of cutting has the smallest effect. The effect of cutting speed is uncertain: it may not affect roughness [2] or roughness may decrease with increasing speed, which is explained by the shorter time of contact of the tool with the workpiece [22].

The literature survey shows that the composites reinforced with continuous fibres are still very difficult to machine [3] and the cutting tool must be harder than the reinforcement. This is why polycrystalline diamond (PCD), which exhibits higher hardness, ensures a longer tool life. However, because of the high cost of PCD, other materials, such as sintered carbides and ceramic compounds, are used for cutting tools. By properly matching the machining parameters, one can increase the effectiveness of each kind of blade. Moreover, the technology of producing aluminum composites reinforced with ceramic fibers has been developed in the Wroclaw University of Science and Technology. These composites are different than the others known composites, as they have specific properties. It is known that the amount, size and kind of reinforcement and properties of composite have a significant bearing on the effects of machining. Hence the authors' interest in this topic, and therefore research was undertaken. The aim of the research was an attempt to evaluate the effectiveness of the diamond blades application in a machining of ceramic-reinforced aluminum composites and manufactured at the Wroclaw University of Technology. This paper presents the results of this research.

\section{TEST CONDITIONS}

A metallic composite material based on an aluminium alloy (AlSi9Mg) matrix, reinforced with ceramic Saffil fibres was subjected to tests. The chemical composition of AlSi9Mg aluminium alloy constituting the matrix is shown in Table 1 while its selected properties are presented in Table 2.

Saffil alumina fibres were used to reinforce the matrix material. Table 3 shows the chemical composition of the Saffil fibres while their selected properties are shown in Table 4. One should note the very high melting point of the Saffil fibres and their high strength properties in comparison with the matrix.

Table 3. Chemical composition Saffil alumina fibres [13]

\begin{tabular}{|c|c|c|c|}
\hline \multirow{3}{*}{ SAFFIL fibres } & \multicolumn{3}{|c|}{ Chemical composition, \% } \\
\cline { 2 - 4 } & $\mathrm{Al}_{2} \mathrm{O}_{3}-\delta$ & $\mathrm{SiO}_{2}$ & $\mathrm{Fe}, \mathrm{Cr}, \mathrm{Ni}, \mathrm{Na}, \mathrm{Mg}, \mathrm{Ca}$, chlorides \\
\cline { 2 - 4 } & $96-97$ & $3-4$ & trace amounts \\
\hline
\end{tabular}

Table 4. Selected properties of Saffil alumina fibres [13]

\begin{tabular}{|c|c|c|c|c|c|c|c|}
\hline \multirow{3}{*}{ SAFFIL fibres } & \multicolumn{9}{|c|}{ Properties } \\
\cline { 2 - 8 } & $\begin{array}{c}\text { Melting } \\
\text { point }{ }^{\circ} \mathrm{C}\end{array}$ & $\begin{array}{c}\text { Tensile } \\
\text { strength } \\
\mathrm{MPa}\end{array}$ & $\begin{array}{c}\text { Young's } \\
\text { modulus, } \\
\mathrm{GPa}\end{array}$ & $\begin{array}{c}\text { Density, } \\
\mathrm{g} / \mathrm{cm}^{3}\end{array}$ & $\begin{array}{c}\text { Mohs } \\
\text { hardness }\end{array}$ & $\begin{array}{c}\text { Diameter, } \\
\mu \mathrm{m}\end{array}$ & $\begin{array}{c}\text { Length. } \\
\mathrm{mm}\end{array}$ \\
\cline { 2 - 9 } & $>2000^{\circ} \mathrm{C}$ & 2000 & 300 & 3.3 & 7 & 3 & $0.1-0.3$ \\
\hline
\end{tabular}


Table 5. Selected properties of the tested material $[13,14]$

\begin{tabular}{|c|c|c|c|c|}
\hline \multirow{3}{*}{ Tested material } & \multicolumn{4}{|c|}{ Properties } \\
\cline { 2 - 5 } & $R_{m}, \mathrm{MPa}$ & $R_{0,2}, \mathrm{MPa}$ & $H B$ & $\alpha, 1 / \mathrm{K}$ \\
\cline { 2 - 5 } & $240-260$ & $160-170$ & $105-115$ & $12-20$ \\
\hline
\end{tabular}

The main positive properties of the fibres reinforcing the tested material are [13]: stability up to $1750^{\circ} \mathrm{C}$, resistance to aggressive chemical compounds, small linear shrinkage, low density, low thermal conductivity, resistance to thermal shocks, high strength, high Young's modulus, uniform fibre diameter, safety in use and large reactive surface area.

The tested material was produced by squeeze casting in the Institute of Production Engineering at Wrocław University of Technology. The composite was produced in two stages. First, a fitting was made of Saffil fibres. Then the ceramic fitting was infiltrated with liquid metal [14].

The tested material is characterized by higher hardness than that of the matrix material. The AlSi9Mg aluminium alloy exhibited a hardness of $74-80$ HB. The composite material with $10 \%$ fibre content, i.e. the material under investigation, exhibited a hardness of 106-124 HB depending on the infiltration pressure used. Moreover, the tensile strength $\left(R_{m}\right)$ of the tested material at room temperature is higher than that of the aluminium matrix. This strength for the AlSi9Mg alloy is within the range: $R_{m}=200-210 \mathrm{MPa}$. The composite material reinforced with a $10 \%$ volumetric Saffil fibre fraction exhibited strength $R_{m}=240$ MPa for the lowest infiltration pressure used and strength $R_{m}=260 \mathrm{MPa}$ for the three times higher pressure. The tested material did not exhibit a clear yield point under tension. This was due to the fact that the proportion of permanent strains relative to elastic strains would increase with load. Therefore, offset yield point $R_{0,2}$ was determined. The composite with the volumetric fibre fraction of $10 \%$ exhibited a higher offset yield point than the matrix, amounting to $160-170 \mathrm{MPa}$ in comparison with 111-125 MPa for the AlSi9Mg alloy. The aluminium composite reinforced with a $10 \%$ Saffil fibre fraction is four times more resistant to abrasion than the matrix $[13,14]$.

The composite material also exhibits lower thermal expansion coefficient values versus temperature than the unreinforced matrix. Up to the temperature of $200^{\circ} \mathrm{C}$ coefficient $\alpha$ increases from 15 to $201 / \mathrm{K}$, whereas below this temperature it decreases to about $121 / \mathrm{K}$. The properties of the aluminium composite material reinforced with Saffil fibres are presented in Table 5. A metallographic polished section of the tested material is shown in Figure $1[13,14]$.

The turning tests were carried out on a universal CNC TUR $560 \mathrm{MN}$ lathe (Fig. 2a). The cutting tools recommended for aluminium alloy machining were used in the tests. Owing to their novel tool materials and the improved design and geometry of the effector part, the tools can be used to machine both soft materials, such aluminium alloys, as well as harder and stronger ones, such as the tested composite material. The tests were carried out using STGCR 2020K-16 turning tool and cutting inserts: TCGX16T304 - Al H10 uncoated sintered carbide insert, TCGX16T304 - Al 1810 diamond coated insert and TCMW 16T3 04F - CD10 polycrystalline diamond insert. The machining parameters characteristic of both roughing and finishing, i.e. $v_{C}=150,450$ and $900 \mathrm{~m} /$ $\min ; f=0.08,0.13$ and $0.27 \mathrm{rpm}$, were applied. The depth of cut was $a_{p}=0.5 \mathrm{~mm}$. The machining tests were carried out respectively under dry machining conditions and with the minimum quantity lubrication (MQL) of the cutting zone with oil mist. A MiniBooster MB II HDC dosing device made by Accu-Lube (Fig. 2b) was used to produce oil mist. The oil mist was fed via two tubes onto the tool flank and face. Fatty alcohol-based oil LB 500

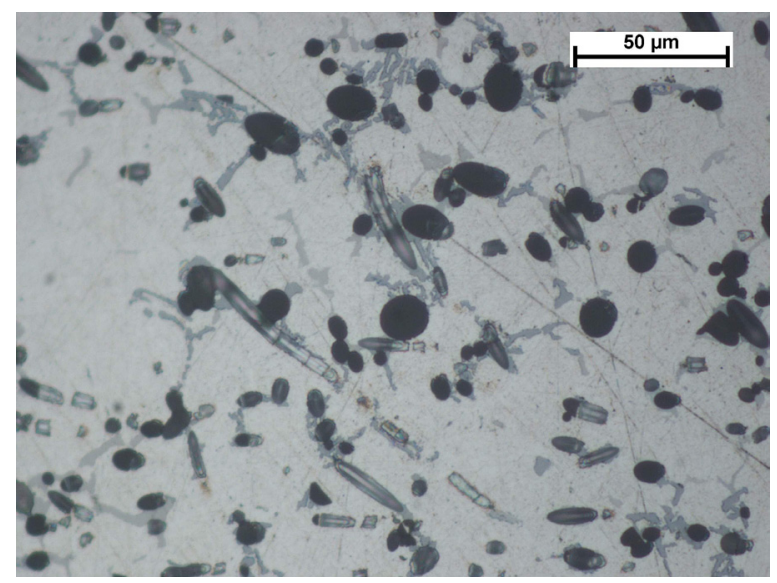

Fig. 1. Metallographic polished section of tested material 
a)

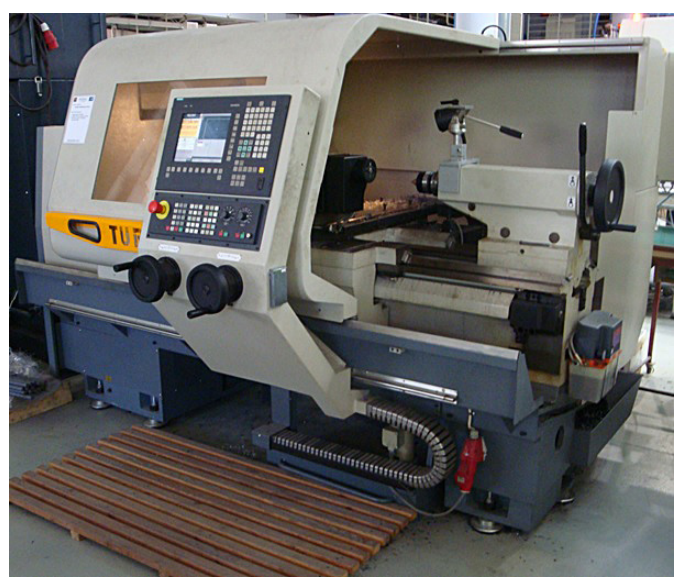

b)

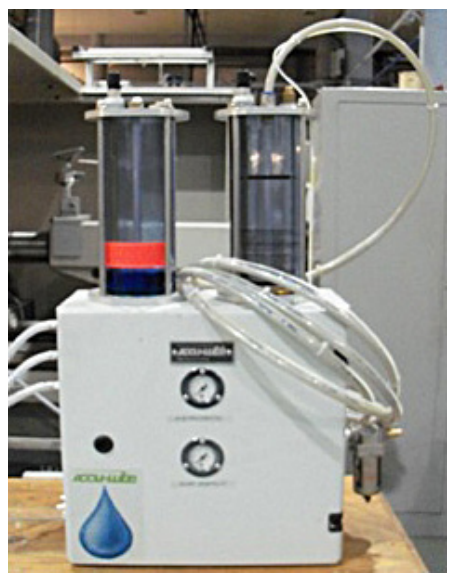

Fig. 2. Test stands a) CNC lathe, b) oil mist producing device

a)

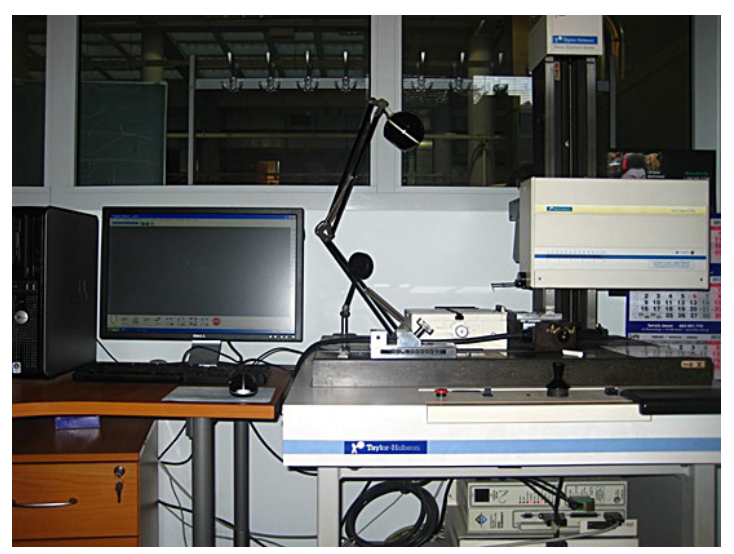

b)

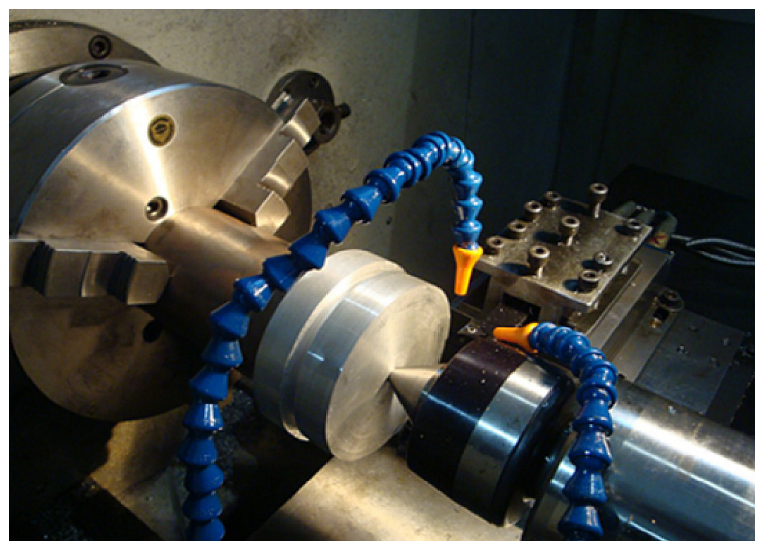

c)

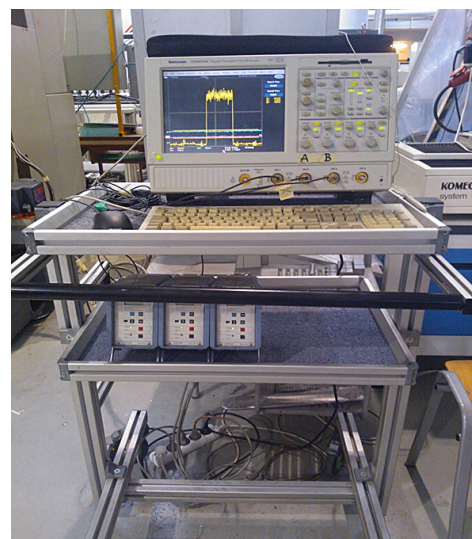

Fig. 3. Test setup, from left: profilographometer, force gauge and oil mist feeding nozzles, signal amplifier and oscilloscope, constituting the cutting force measuring circuit

recommended for machining aluminium was used. The oil is nontoxic and environmentally safe. Another advantage is that it does not leave stains or deposits on the machined surface.

A Taylor Hobson Form Talysurf 120L profilographometer (Fig. 3) was used to measure roughness. Roughness measurements were performed in three places spaced at every $120^{\circ}$ on the perimeter of the turned surface. The measuring length amounted to $20 \mathrm{~mm}$. The cutting forces were measured by means of a measuring circuit (Fig. 3) consisting of: a Kistler 9257A piezoelectric force gauge, a signal amplifier type 5011 and a Tektronix Digital Phosphor Oscilloscope TDS 5054B. 


\section{TEST RESULTS}

Figures 4 and 5 show the results of roughness measurements for the surface of the tested composite turned with carbide and diamond blades. The basic roughness parameters most often used in industry, i.e. $R a$ and $R z$, were selected for the analysis. Consistently with the theory, the roughness of the surface machined with each of the tools depends on the feed rate. The values of the $R a$ and $R z$ parameters increase quadratically as the feed rate increases. In the feed rate range $f$ $=0.08-0.13 \mathrm{~mm} / \mathrm{rev}$. roughness changes slightly, but when the feed rate is increased to $0.27 \mathrm{~mm} /$ rev., it changes significantly. Comparing the tools used, one can notice that for dry turning with the polycrystalline tools at feed rates up to $0.13 \mathrm{~mm} /$ rev., one can obtain similar, and sometimes even better surface roughness than the one obtained by means of the coated and uncoated carbide blades. However, for the feed rates used in high performance machining, better surface quality was obtained after turning with uncoated carbide blades and the best quality after machining with a diamond coated insert. The disadvantageous difference was reduced when machining was carried out at the minimum quantity lubrication (MQL) of the cutting zone. Moreover, the use of oil mist had a very beneficial effect on the surface turned with uncoated carbide blades. No such positive effect of MQL was observed on the surfaces machined with the polycrystalline diamond blades
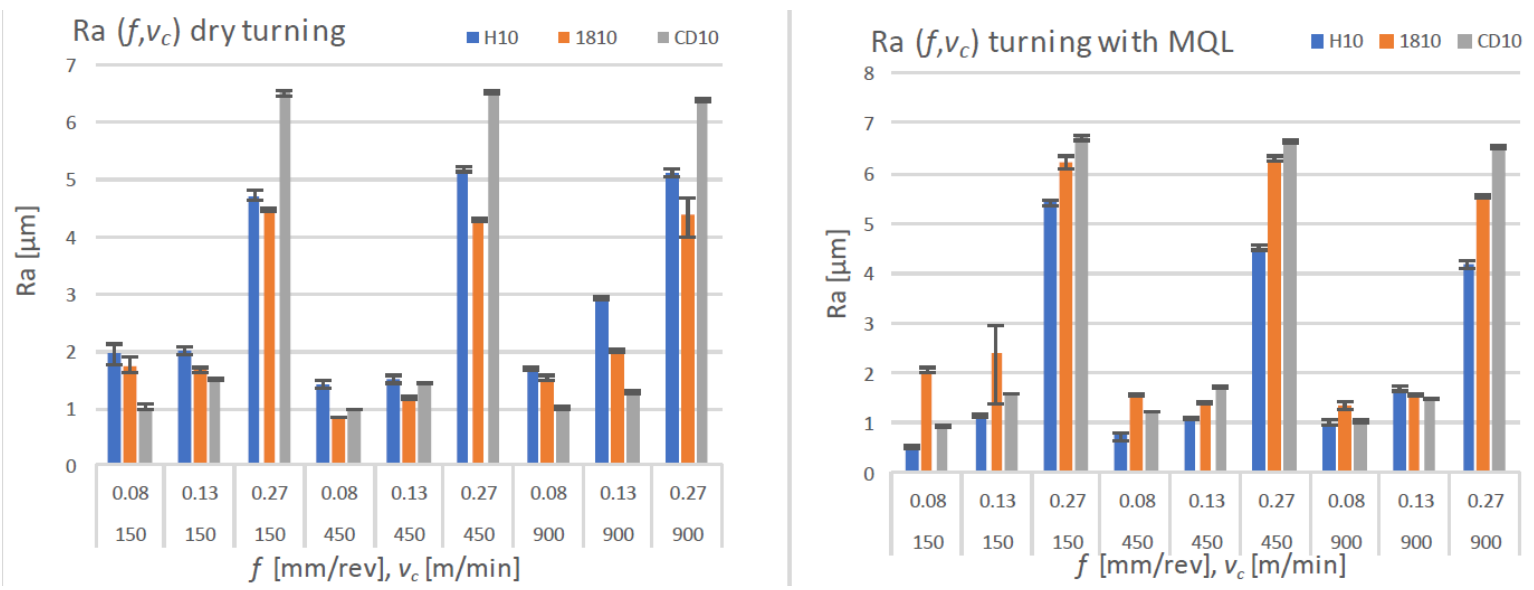

Fig. 4. Surface roughness Ra versus feed rate $f$ and cutting speed $v_{C}$ for Saffil fibre-reinforced aluminium composite material turned with respectively uncoated carbide blade, diamond coated blade and polycrystalline diamond blade
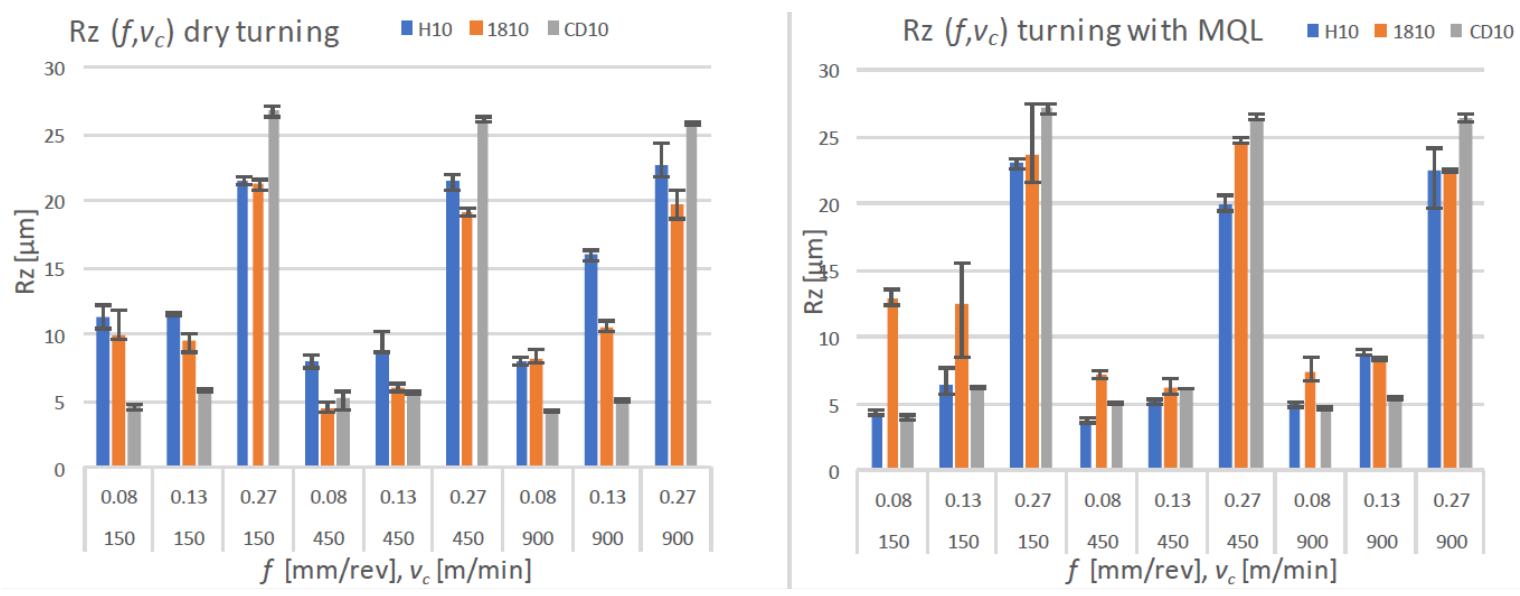

Fig. 5. Surface roughness $R z$ versus feed rate $f$ and cutting speed $v_{C}$ for Saffil fibre-reinforced aluminium composite material turned with respectively uncoated carbide blade, diamond coated blade and polycrystalline diamond blade 
and the diamond coated inserts, respectively. It should be noted that when the diamond tools are used, the scatter of roughness measurement results decreases considerably and higher machining effect repeatability is obtained. It can also be concluded that using either carbide blades or diamond blades, it is possible to obtain the composite's surface with roughness $R a$ below $1 \mu \mathrm{m}$, whereby it will not be necessary to subject composite parts to abrasive machining, e.g. grinding. This obviously will be possible in the cases when no geometric composite surface structure with random tool marks is required.

While analysing the results of measurements of the cutting force components (Figures 6-8) for the turning of the tested material with a polycrystalline diamond insert, it can be concluded that consistently with the theory, the differences between the values of the particular force components for dry turning are approximately as follows: $F f=(0.3-0.4)^{*} F C$ and $F p$ $=(0.6-0.7) * F c$. Under the minimum quantity lubrication conditions, the above-mentioned relations are as follows: $F f=(0.3-0.4) * F C$ and $F p=(0.5-0.6) * F c$. Moreover, the variation in the cutting force depending on the rate of feed is consistent with the theory. The effect of the cutting speed is negligible.

The use of oil mist for the cooling and lubrication of the cutting zone had a positive effect on the cutting force values. Under all the adopted turning conditions, except for the machining at
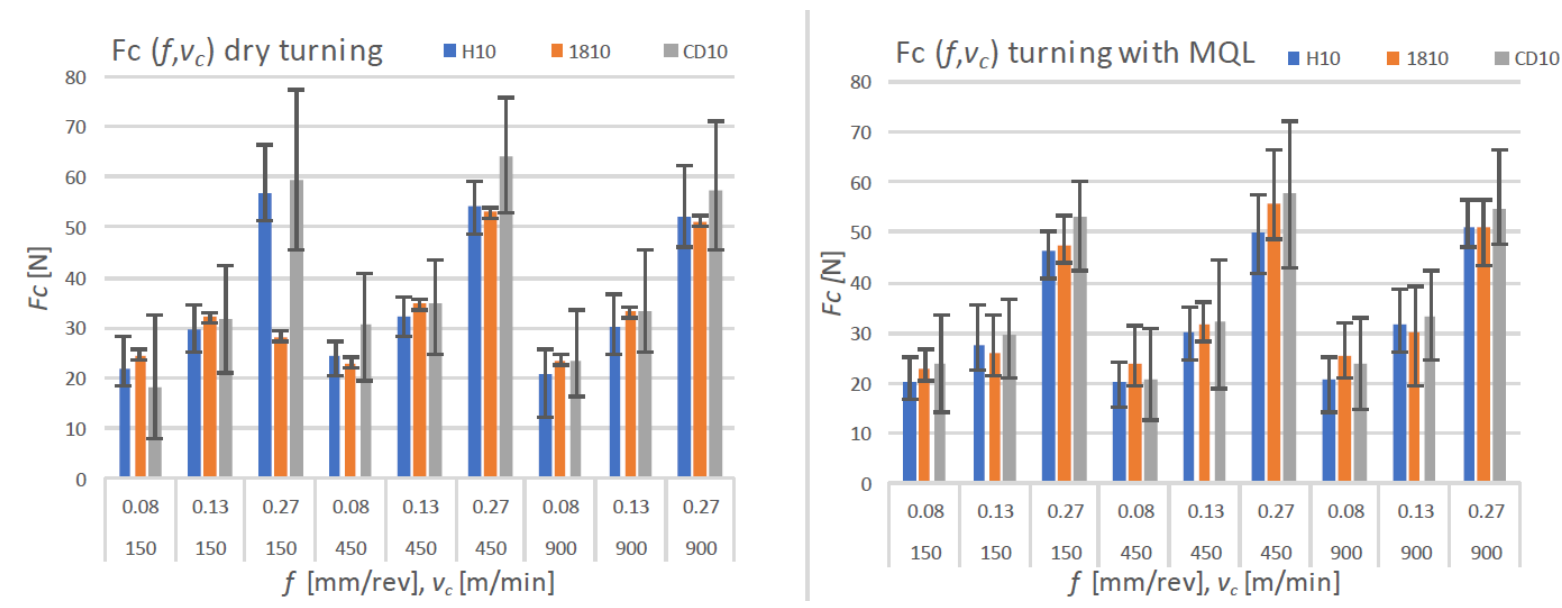

Fig. 6. Main cutting force component Fc (average value) versus feed rate $\mathrm{f}$ and cutting speed vc for the Saffil fibre-reinforced aluminium composite material turned with uncoated carbide blade, diamond coated blade and polycrystalline diamond blade, respectively
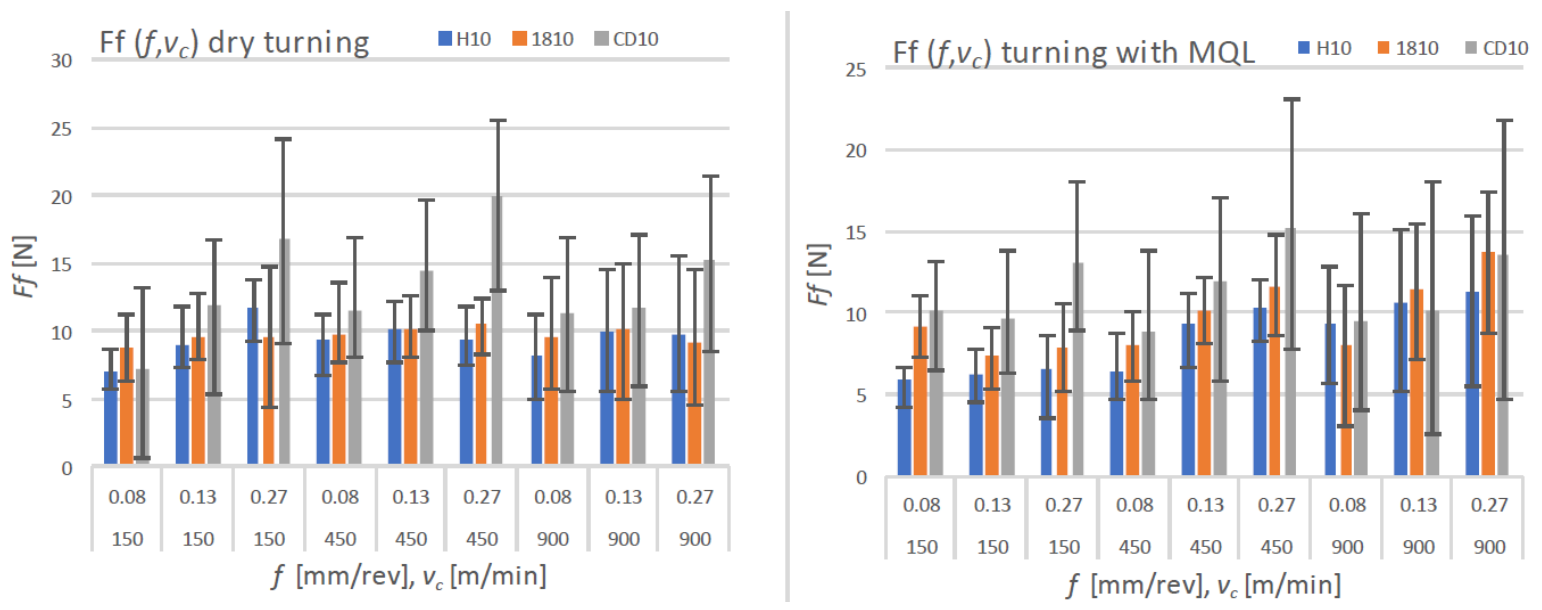

Fig. 7. Cutting force feed component Ff (average value) versus feed rate f and cutting speed vc for the Saffil fibre-reinforced aluminium composite material turned with uncoated carbide blade, diamond coated blade and polycrystalline diamond blade, respectively 
the lowest feed rate and cutting speed, a reduction in the cutting force was observed. The strongest positive effect of MQL was obtained for the thrust force component $\mathrm{Fp}$ and feed force component $F f$. The measured force values were lower by as much as $25 \%$. The positive effect of MQL on main component $F C$ amounted to about 10\%.

A comparison of the cutting force measurement results for all the blades used shows that the polycrystalline diamond blade generates the highest values of all the force components. This effect is visible for all the adopted machining parameters, but it is particularly high for feed rate $f=0.27 \mathrm{~mm} / \mathrm{rev}$. The geometry and material of the blade can be the determining factors here. The diamond tool differs markedly in the shape of its face. In addition, its material has lower impact strength than sintered carbide, whereby higher pressures can be generated. It is also possible that the absence of a chip breaker on the polycrystalline diamond plate, resulting in longer chips, contributed to an increase in the vibrations of the machine tool-holder-workpiece-tool system, whereby the cutting forces increased significantly. At the feed rate of $0.27 \mathrm{~mm} / \mathrm{rev}$., the carbide blades would break chips and shorten their length, whereas during machining with diamond plates, the chips were very long. No differences in chip length were observed at the feed rate of $0.08 \mathrm{~mm} /$ rev. (Fig. 9).

The polycrystalline diamond blades should be more durable that the uncoated carbide blades. One can also assume that their abrasive wear will be less intensive than that of diamond coated blades, despite the stronger cutting forces. In order to corroborate these assumptions, the face and
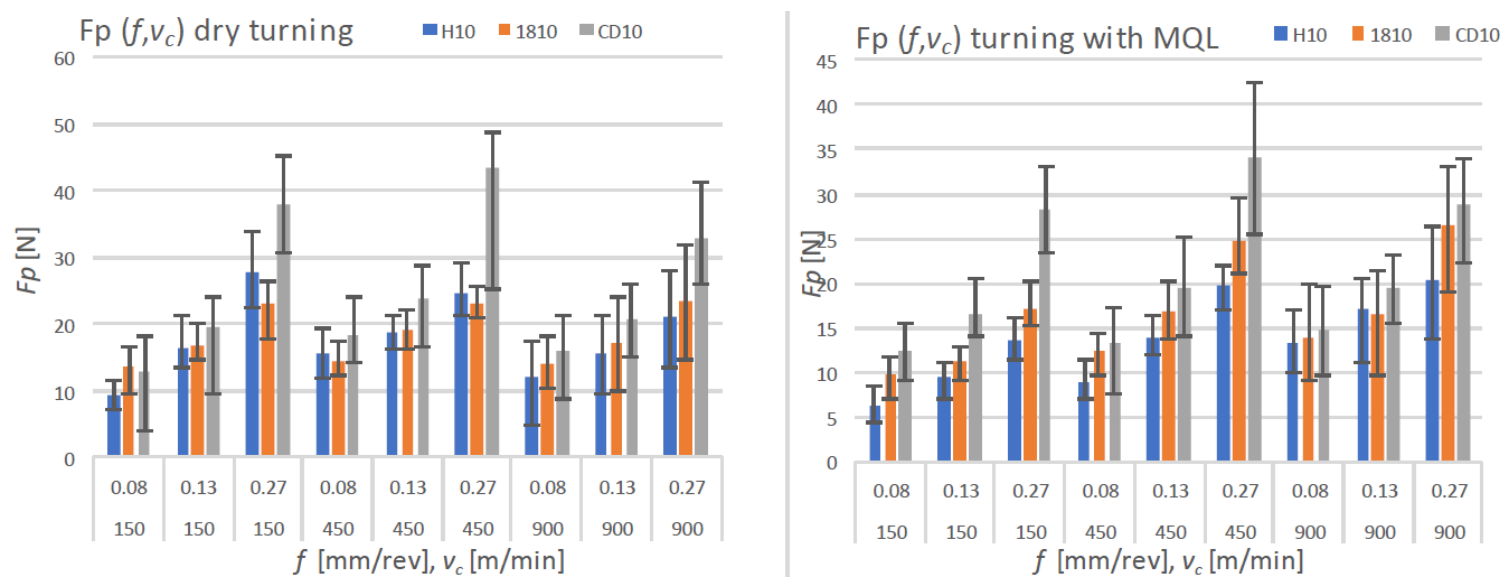

Fig. 8. Cutting force thrust component $F p$ (average value) versus feed rate $f$ and cutting speed $V_{C}$ for the Saffil fibre-reinforced aluminium composite material turned with uncoated carbide blade, diamond coated blade and polycrystalline diamond blade, respectively
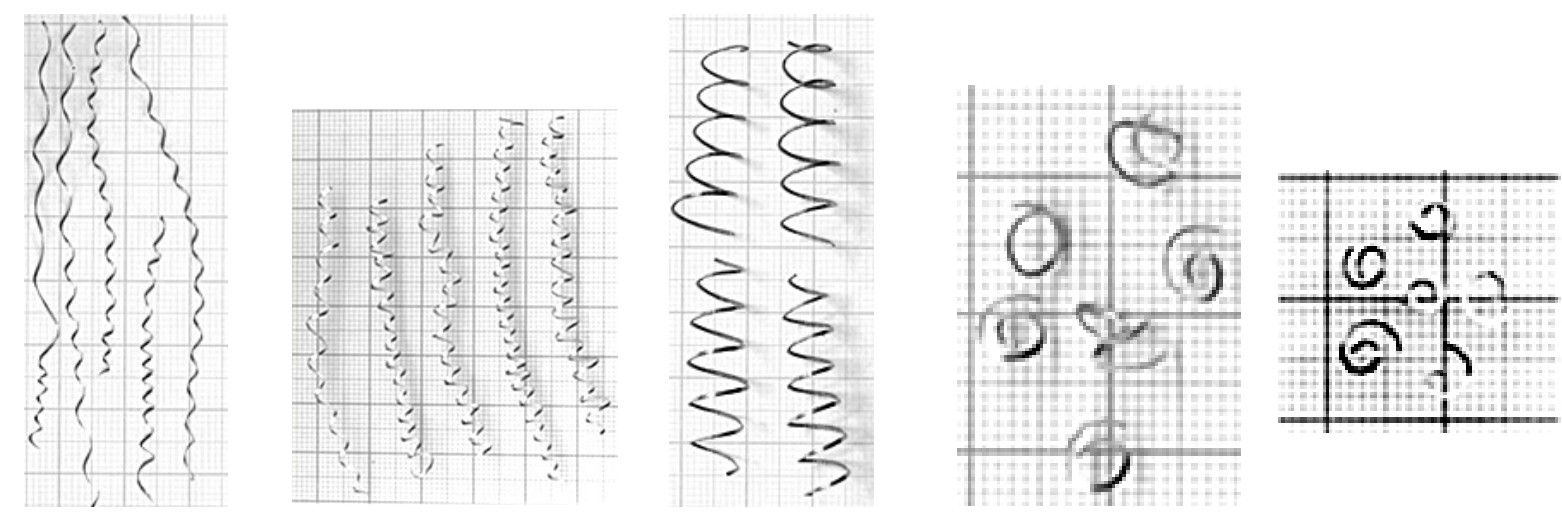

Fig. 9. Chips obtained during turning of aluminium composite material with: a) diamond plate at feed rate $f=0.08 \mathrm{~mm} / \mathrm{rev}$., b) carbide plate at feed rate $f=0.08 \mathrm{~mm} / \mathrm{rev}$., c) diamond plate at feed rate $f=0.27 \mathrm{~mm} / \mathrm{rev}$. and d), e) carbide plate at feed rate $f=0.27 \mathrm{~mm} / \mathrm{rev}$ 
Table 6. Photographs of the faces and flanks of the blades used in tests, taken after the experiment was completed

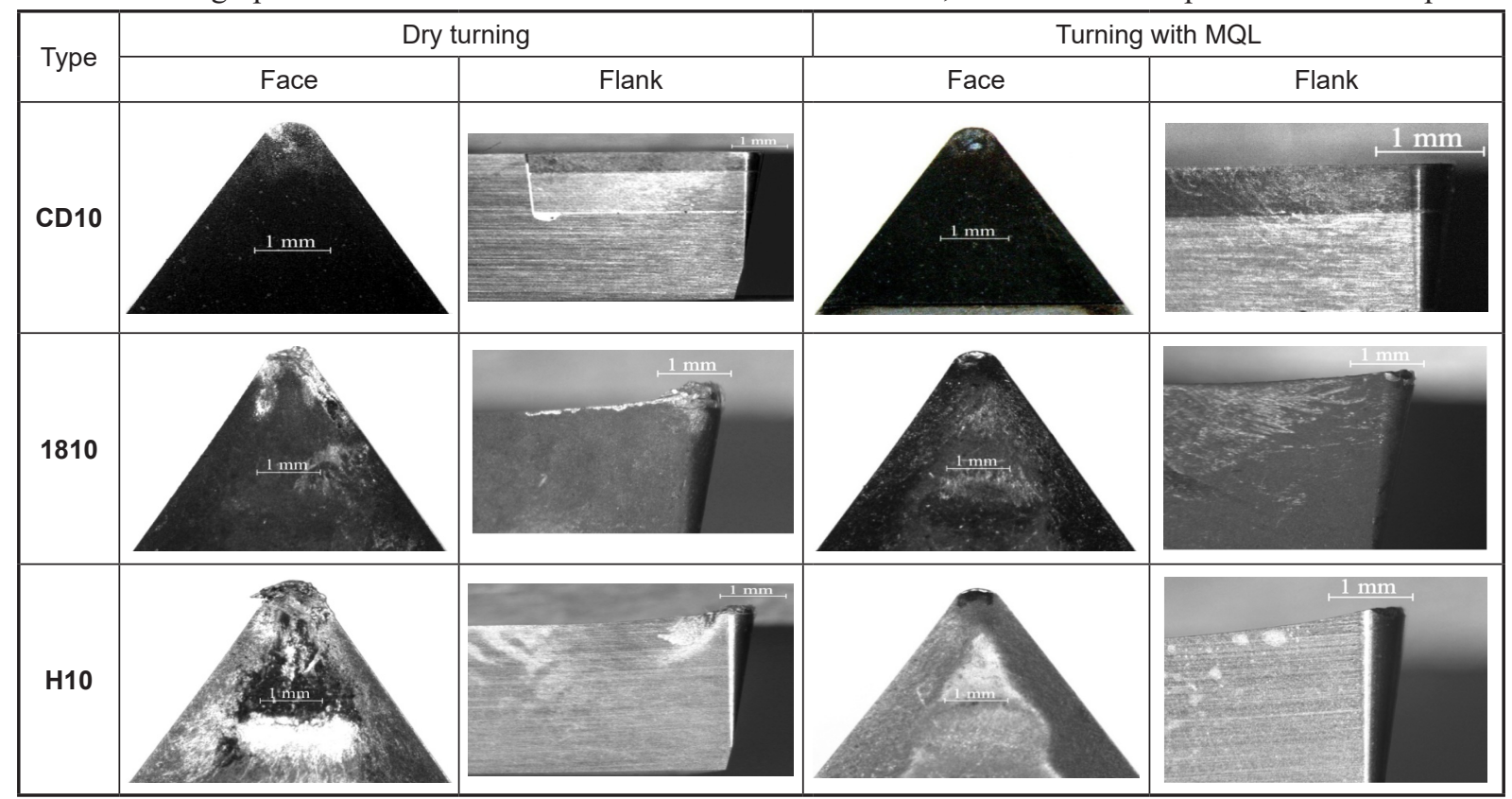

flank surfaces of the cutting plates were examined under microscope. The photographs of the blades after machining were taken under ZEISS Stereo Discovery V.20 microscope. Because the number of carried out tests was too small and their duration too short, it is not possible to fully assess the wear of the tools, determine their wear over time and unequivocally compare the degrees of blunting of all the blades (Table 6). Hence, only comparative photographs, without measurements of dulling criteria are presented. Nevertheless, several conclusions can be drawn from the photographs and the assumption concerning the likely longer life of the diamond blades can be corroborated. After dry turning, all the blades show some wear, but the uncoated carbide blade clearly shows the highest degree of wear. The wear is visible on both its face and flank. The diamond coated insert also shows considerable wear, which is heavier than on the plate with a diamond insert. It should be noted that the wear of all the blades is much smaller after turning with the minimum quantity lubrication of the cutting zone and the polycrystalline diamond blade shows only slight wear.

\section{CONCLUSIONS}

The results of the turning tests carried out on the aluminium composite material reinforced with long Saffil ceramic fibres were presented. Generally available tools recommended for the machining of aluminium alloys, such as the matrix of the tested composite, were used. The tools were: uncoated carbide plates, diamond coated plates and polycrystalline diamond plates. The aim of the investigations was to find out if the use of much more expensive diamond tools offers wider machining possibilities and improves the main effects of the machining of composites. Due to the abrasive action of their reinforcement, ceramic-reinforced composite materials are difficult to machine, whereby the blades used for their machining wear out faster. The investigations showed that the necessity of frequent blade replacement can be reduced through the use of polycrystalline diamond plates, since diamond wears out much slower. This reduction can certainly favourably affect the efficiency of the machining of the tested composites. An analysis pertaining to the results of the measurements of the other tool cutting ability indicators showed that:

- the surface after turning with each of the tools is shaped consistently with the kinematic-geometric mapping, no anomalies were observed;

- for finishing feed rates (up to $0.13 \mathrm{~mm} / \mathrm{rev}$.) lower values of the $R a$ and $R z$ roughness parameters were obtained for turning with the polycrystalline diamond blade;

- for performance feed rate $f=0.27 \mathrm{~mm} / \mathrm{rev}$. higher surface quality was obtained for machining with carbide inserts; 
- the differences between the surface quality after turning with respectively the diamond tools and the carbide tools disappear in the case of machining with the minimum quantity lubrication of the cutting zone;

- MQL was found to have the strongest positive effect on the surface quality for machining with the uncoated carbide tools;

- in terms of the surface quality, the most stable machining is turning with diamond blades;

- using diamond tools, one can obtain a surface with roughness $R a$ below $1 \mu \mathrm{m}$;

- the diamond material of the blade and the latter's geometry without a chip breaker contribute to the generation of greater cutting forces than in the case of the carbide tools;

- the use of oil mist reduces the cutting force components by $10-25 \%$ during turning with the diamond plate; therefore, instead of dry turning, it is recommended to use the minimum quantity lubrication of the cutting zone;

- because of the absence of a chip breaker on the diamond plates long chips were obtained in the whole adopted parameter range; as opposed to the chips obtained during machining with the carbide tools, no shortening of the chips at an increasing feed rate was observed.

\section{REFERENCES}

1. Andrewes C.J.E, Feng H.Y, Lau W.M: Machining of an Aluminium/SiC Composite using Diamond Inserts. J Mater Process Technol 102, 2000, 25-29.

2. Bansala P., Upadhyay L.: Effect of Turning Parameters on Tool Wear, Surface Roughness and Metal Removal Rate of Alumina Reinforced Aluminum Composite. Procedia Technology 23, 2016, 304-310.

3. Bhardwaj A.R., Vaidya A.M., Shekhawat S.P.: Machining of Aluminium Metal Matrix Composite: A Review. Materials Today: Proceedings 21, 2020, 1396-1402.

4. Bian R., He N., Li L., Zhang Z.B., Wu Q., Shi Z.Y.: Precision milling of high volume fraction $\mathrm{SiCp} /$ Al composites with monocrystalline diamond end mill. International Journal of Advanced Manufacturing Technology 71(11), 2014, 411-419.

5. Chambers A.R.: The machinability of light alloy MMCs Composites. Composites Part A: Applied Science and Manufacturing, 27(2), 1996, 143-147.

6. Chambers A.R., Stephens S.E.: Machining of Al 5Mg reinforced with 5 vol.\% Saffil and 15 vol.\% SiC. Materials Science and Engineering, 135, 1991, 287-290.
7. Hariprasad et al., Wear Characteristics of B4C and A12O3 Reinforced with Al 5083 Metal Matrix based Hybrid Composite. Procedia Engineering 97, 2014, 925-929.

8. Kishawy, H. A, Kannan S and Balazinski. M.: An energy-based Analytical Force Model for Orthogonal cutting of Metal Matrix Composites. CIRP Annals - Manufacturing Technology, (53)1, 2004, 91-94.

9. Lane C.T.: Machining of Particulate- Reinforced Aluminium, Fabrication of Particles Reinforced Metal Composites, International Conference, Montreal, 1999, 195-201.

10. Li X., Seah W.K.H.: Tool wear acceleration in relation to workpiece reinforcement percentage in cutting of metal matrix composites. Wear 247, 2001, 161-167.

11. Morteza Alizadeh, Mostafa Alizadeh, Rasool Amini: Structural and Mechanical Properties of Al/B4C Composites Fabricated by Wet Attrition Milling and Hot Extrusion, Journal of Materials Science \& Technology, Volume 29, Issue 8, August 2013, 725-730.

12. Muthukrishnan N., Paulo Davim J.: Optimization of machining parameters of $\mathrm{Al} / \mathrm{SiC}-\mathrm{MMC}$ with ANOVA and ANN analysis. Journal of Materials Processing Technology, 209(1), 2009, 225-232.

13. Naplocha K., Samsonowicz Z.: Twardość materiałów kompozytowych o zwiększonej zawartości włókien. Kompozyty (Composites) 12, 2001, 199-202.

14. Naplocha K., Samsonowicz Z.: Mechanizm pękania materiałów kompozytowych na osnowie stopu A1Si9Mg umacnianych włóknami. Kompozyty (Composites) 24, 2002, 238-241.

15. Nicholls C.J., Boswell B, Davies I.J., Islam M.N., Review of machining metal matrix composites. Int. J. Adv. Manuf. Technol. 90, 2017, 2429-2441.

16. PN-EN 1706:2001.

17. Prakash Rao C.R, Bhagyashekar M.S, Narendraviswanath: Effect of Machining Parameters on the surface roughness while turning Particulate Composites. 12th Global congress on Manufacturing and Management, GCMM 2014. ScienceDirect Procedia Engineering 97, 2014, 421-431.

18. Pugazhenthi A., Kanagaraj G.,, Dinaharan I., David Raja Selvam J.: Turning characteristics of in situ formed TiB2 ceramic particulate reinforced AA7075 aluminum matrix composites using polycrystalline diamond cutting tool. Measurement 121, 2018, 39-46.

19. Puneet Bansal, Lokesh Upadhyay: Experimental Investigations To Study Tool Wear During Turning Of Alumina Reinforced Aluminium Composite. Procedia Engineering, 51, 2013, 818-837. 
20. Rajkumar K., Rajan P., Maria Antony Charles J.: Microwave Heat Treatment on Aluminium 6061 Alloy-Boron Carbide Composites. Procedia Engineering, 86, 2014, 34-41.

21. Sekhar R., Singh T.P.: Mechanisms in turning of metal matrix composites: a review. J. Mater. Res. Technol. 4, 2015, 197-207.

22. Siddesh Kumar N.G., Shiva Shankar G.S., Ganesh M.N., Vibudha L.K.;: Experimental Investigations to Study the Cutting Force and Surface Roughness during Turning of Aluminium Metal Matrix Hybrid Composites. Materials Today: Proceedings 4, 2017 , 9371-9374.

23. Sivasankarana S., Harisagarb P.T., Saminathanb E., Siddharthb S., Sasikumarb P.: Effect of Nose Radius and Graphite Addition on Turning of AA
7075-ZrB2 in-situ. Composites Procedia Engineering 97, 2014, 582-589.

24. Ubeyl M., Acir A., Serdar Karakas M., Ogel B.: Effect of Feed Rate on Tool Wear in Milling of Al-4\%Cu/B4Cp Composite. Journal Materials and Manufacturing Processes, 23(8), 2008, 945-950.

25. Varadarajan Y. S, Vijayaraghavan L, Krishnamurthy R.: The machinability characteristics of aluminosilicate fibre reinforced Al alloy composite. Mater Manufacturing Process, 17, 2002, 811-824.

26. Wang T., Xie L., Wang X., Ding Z.: PCD tool performance in high speed milling of high volume fraction $\mathrm{Si} / \mathrm{Cp} / \mathrm{Al}$ composites. International Journal of Advanved Manufacturing Technology, 78, 2015, 1445-1453. 